Received: January 22, 2021 / Accepted: March 25, 2021 / Published online: July 2, 2021 The (C) Author(s) 2021. This article is published with open access at Academia Analitica

ORIGINAL SCIENTIFIC PAPER

UDC: $72.01: 316.258$

\title{
Liminality as an Autopoietic Process within (Spatial) Identity
}

\author{
Katarina Bošnjak ${ }^{1}$
}

\begin{abstract}
Spatial identity surpasses geographical boundaries of a certain space, and denotes not only physical characteristics of space, but its meaning to people that use it, as well as their intercommunication, which produces new social and spatial meaning. Unless there is an abrupt change in social structure or formal/functional transformation of (un)built environment, we perceive spatial identity as something almost permanent. However, it is in a constant state of change, existing in a present state that relies on our past experiences and contains projections of our future, maintained through constant background processes of disorganization and concomitant organization - in other words, identity is in the state of (perpetual) liminality. Liminality is the product, as well as the initiator of autopoietic processes within identity, which leads to the main premise of this article - (spatial) identity is an autopoietic system. This is analyzed through three chosen aspects of place attachment: ritual, memory and architecture.
\end{abstract}

Key words: autopoiesis, spatial identity, liminality, Niklas Luhmann, place

\footnotetext{
${ }^{1} \mathrm{~K}$. Bošnjak

University of Sarajevo, Faculty of Architecture

Patriotske lige 30, Sarajevo 71000, Bosnia and Herzegovina

bos.katarina@gmail.com
} 


\section{Introduction}

Since abandonment of the idea that space has merely a geometrical meaning, the relation between people and space has been the subject of many discussions and considerations. Through history, intuitive choices of habitation sites have resulted in certain principles that became inherent ideas and expectations we have from our physical and social environment. Historical layers of physical settings, social organization, as well as activities and interdependent transformational processes resulted in diversity of cultural articulation of spaces we inhabit. Through inhabitation and our participation in space creation and representation, we create bonds with space - place attachment, that is incorporated in spatial identity, as well as personal and collective identity. Place attachment can be perceived as a bridge between personal, collective and spatial identity, and in this article it will be elaborated through three aspects - the ritual, memory and architecture. The aspect of ritual is chosen as an ethereal element of intention in the creation of architecture, which lingers through the temporal progression of (spatial) identity creation. Temporal progression reveals the aspect of memory and its role in palimpsest creation of (spatial) identity landscape. Finally, this memory and identity landscape is most recognizable through the aspect of architecture as a physical embodiment of peoples' layered intentions through time and space.

Spatial identity surpasses geographical boundaries of a certain space, and denotes not only physical characteristics of space, but its meaning to people that use it, as well as their intercommunication, which produces new social and spatial meaning, that become new habitus. Most of the time, unless there is an abrupt change in social structure or formal/functional transformation of (un)built environment, we perceive spatial identity as something almost permanent. However, it is in a constant state of change, existing in a present state that relies on our past experiences and contains projections of our future. In order to avoid degradation of identity, it is maintained through constant background processes of disorganization and concomitant organization, which discloses numerous directions it can take. The loss of stability leads to the realm of adaptability, where identity evolves through "increasing its complexity, increasing its capacity to anticipate changes within the environment, increasing its control over the immediate environment or suitably combining all the above" (Aquile, Lekovic, \& Sanchez, 2014: 64-65).This transitional degradation and stabilization of identity is a threshold between two relatively stable states - in other words, identity is in the state of (permanent) liminality. 
Permanent liminality is the product, as well as the initiator of autopoietic processes within identity.

Liminality (lat. limen - threshold) is an anthropological concept developed by Arnold van Gennep, which implies the ambiguity that occurs at the transition from one status to another during a transformation, when something is on the border between the previous state and the new one, whilst having characteristics of both states, but not enough to actually belong to either (Turner, 1974). Application of this concept transgressed to elucidation of processes and states that occur during adaptable and fluid state of ideology and social structure transformation, interruptions of tradition continuity, description of development of (real and imaginary) beings and spaces, that is susceptible to establishment of new institutions and customs.

The main premise of this article is that (spatial) identity is an autopoietic system, and it will be contemplated through transgression of the concept of liminality within (spatial) identity and the factors that lie beneath its transformation, whilst regarding these factor as autopoietic communication events that maintain its autopoiesis.

\section{The Concept of Autopoiesis}

The concept of autopoiesis was developed by cognitive biologists Humberto Maturana and Francisco Varela in the sixties in regards to living systems, and Niklas Luhmann transgressed the concept of autopoiesis to social and psychic systems ${ }^{2}$. However, social and psychic system interpenetrate each other and constitute environment for each other. The autopoietic system is a system that recursively reproduces its elements through its own elements (Varela, Maturana, \& Uribe, 1981). Central to the concept of autopoiesis is the idea that the different elements of the system interact in such a way as to produce and reproduce the elements of the system - meaning, the system reproduces itself. In this sense, the autopoietic system is operatively closed, but interactionally open through its contact with the environment. This means that the system receives irritations - triggers for internal processes in the system from the environment, but not direct inputs that determine those processes. The response of the system is determined by the structure of the system (Seidl, 2004).

\footnotetext{
${ }^{2}$,While living systems reproduce themselves on the basis of life, social systems reproduce themselves on the basis of communication and psychic systems on the basis of consciousness or thoughts, their elements are not physical substances but elements of meaning“" (Seidl, 2004).
} 
As said, one of the premises of this article is that identity is an autopoietic system. (Spatial) identity is a complex phenomenon, an amalgamation of various processes interacting with each other. One could say that identity is a component of a system, especially if we analyze it within closed boundaries of its certain aspect (person, community, nation, neighborhood, city...), however, it is more suitable to say that these aspects are united in a system that is operatively closed on the basis of a specific binary coding that stems from their communications. In this context, liminality is an operative process reacting to the interactions of elements of the system identity. Complexity of identity as a system will be elaborated in the Chapter 3.

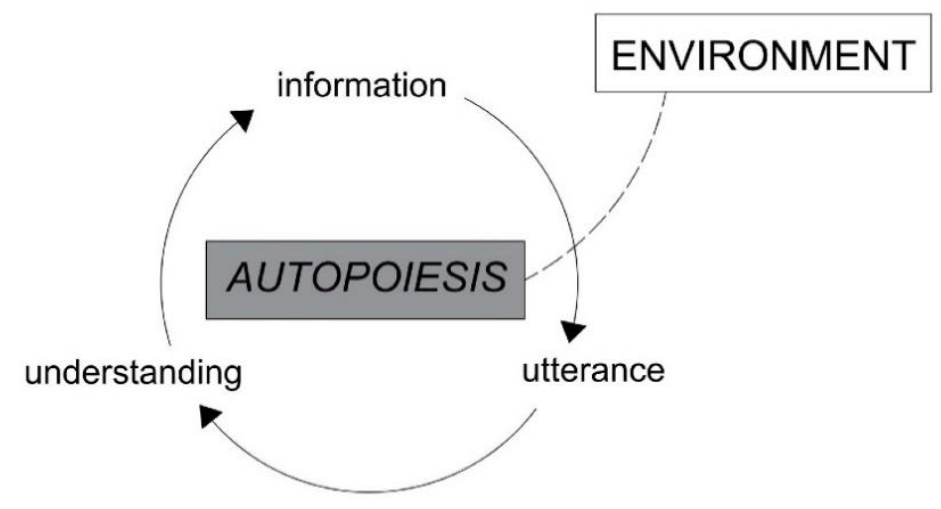

Figure 1. Autopoietic reproduction, according to Luhmann (illustration: Katarina Bošnjak, March 2021.)

Luhmann (in: Seidl, 2004:7) suggests that communications are mode of autopoietic reproduction - they are recursively (re)produced by a network of communication and cannot exist outside of it. He conceives of communication as a combination of three components: information, utterance and understanding. So if we regard (spatial) identity as a communication system, components of its communication would be the three aspects of place attachment - ritual, memory and architecture as information; utterance, as a manner of how and why the information is conveyed refers to ideological, political, socio-physical representation of these information. However, understanding determines how information is perceived through cognizance of its meaning. Meaning of an information and its utterance depends on the structure of the (identity) system. Finally, once the information within the (spatial) identity is understood, it can be rejected or accepted as part of the system, which connects communicative "events" that take place within the (identity) system. In context of spatial identity, this stage is achieved through place attachment. This is a gross simplification of concept of ritual, memory and architecture, since they are complex constructs of the social system, but it indicates the complexity of 
(spatial) identity as a continuous system that is in the state of everlasting recomposition - or in the state of permanent liminality maintained through autopoiesis. For this reason, the role of liminality within the (spatial) identity is elaborated later, through analysis of process of place attachment as a bridge between personal, collective and spatial identity.

\section{Identity - Permanence of Betwixt and Between}

To understand the process of autopoiesis within the system of (spatial) identity, it is necessary to recognize the processes and mechanisms behind (spatial) identity creation, in general. These processes are liminal themselves through incoherence of identity caused by the perception of Otherness.

Personal identity is ones' perceived sense of self, through awareness and manifestations of ones' idiosyncrasies. It is not inherited, nor permanent, and it is not internally created, but externally discovered. This discovery of personal identity is mediated by reflection of other people, their interactions with ones' self, and spatial bonds we create, meaning that personal identity is not an isolated phenomenon, but socially and spatially influenced - in fact, it is constituted of social embeddedness of collective and spatial identity.

Collective identity refers to an image and imaginarium created by the members of certain group that perceive their integrity through idiosyncrasies of the group, as well as projected image and agendas that members of the group take as their own. We can draw a parallel between Benedict Anderson's idea $(1983,2006)$ of imagined communities and collective identity. Even though Anderson analyzes nations and nationalism as a form of social constructions resulting in imagined communities, the principles of nation making and making of collective identity are the same narrative of historical background creates an image from the past maintained through symbolism and customs in the present, and projected in the future by ideologies and beliefs. The community (or collective) is usually so vast that the people recognizing and proclaiming their belonging and identification to it do not know each other, but the created and maintained imaginarium is something that overcomes the need for personal acquaintance. Imaginarium of collective (identity) is reflected in personal identity through rational and emotional association with the elements that signify it. Being part of a collective is an act of externalization of an image of ourselves - imago, that we create through exploration of personal identity. 
Personal and collective identity is framed by spatial setting, reflected in its real and imaginative geography (see: Said, 1978, 1995, 2003). Even though we live and act in real, objective geographical setting, our identification is achieved through the domain of imaginative ${ }^{3}$ - imagery, discourse, text, symbols, rituals - representation of space through emphasis of its' image - imago. These are the means of achieving place attachment that is the bridge between personal, collective and spatial identity. Concept of place attachment will be analyzed in more detail in the next chapter.

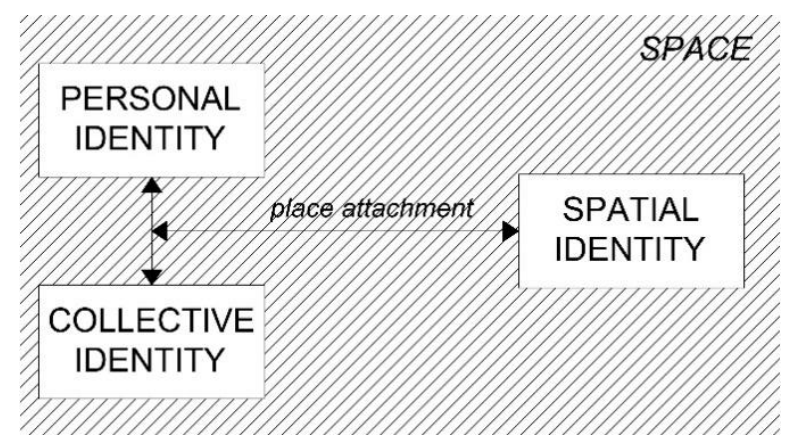

Figure 2. Identity system (illustration: Katarina Bošnjak, February 2021.)

Since we achieve spatial identity through the domain of the perceived and representational, it is important to understand the relativity of its positionality, since it is the source of diversity and societal and spatial Otherness. Although identity is framed and enclosed in its' unity, it is achieved through constant reflection of surrounding difference and distinction, so we recognize what we are by being aware of what we are not - via process of Othering. This process ensures that identity as a system is relative and subject to interpretation, thus changeable and liminal, since its elements, through relativity of their perception can interact with each other to (re)produce new elements. In order to place the space in this process, we can observe it through concept of Lacan's mirror (see: Lacan, 2006).

${ }^{3}$ Said does not equate imaginative with false, but with perceived. 


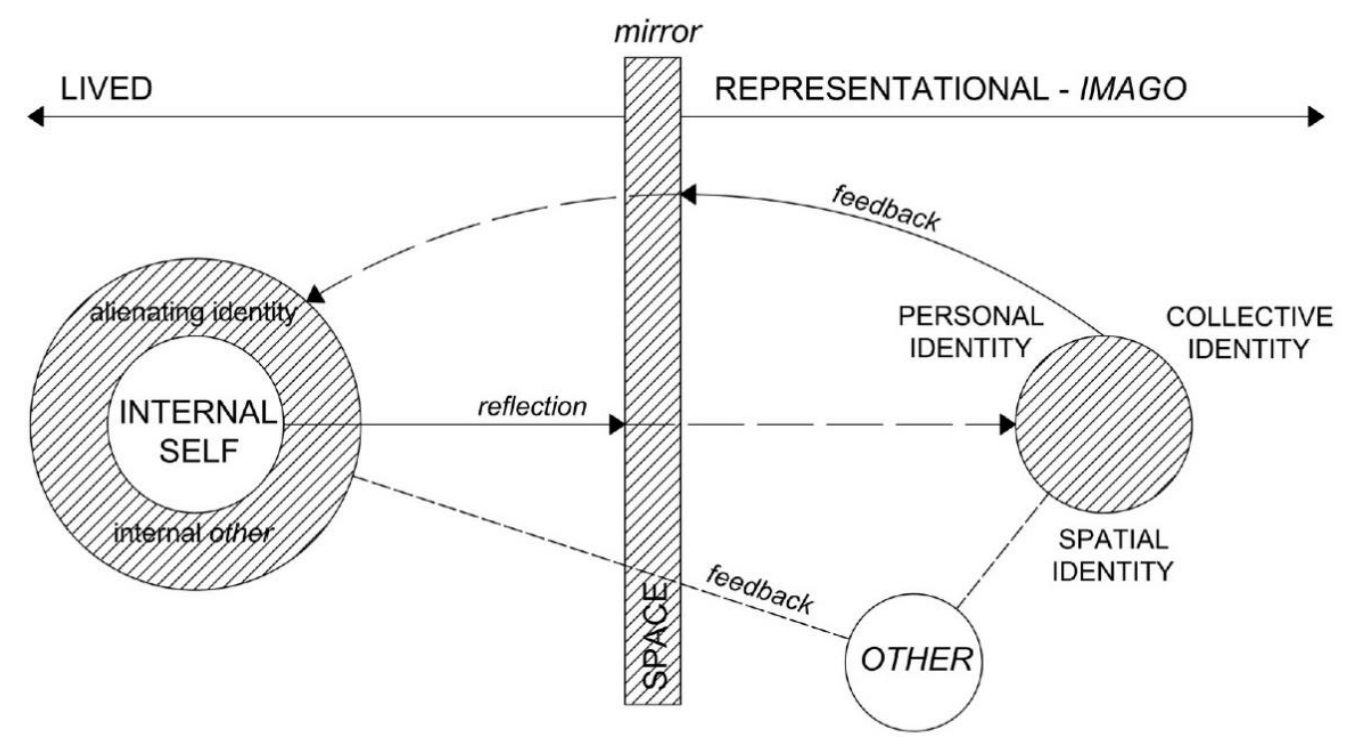

Figure 3. Process of Othering in identity system (illustration: Katarina Bošnjak, March 2021.)

When we subjectively reflect on the world around us, which we perceive through representational (imaginative) value - the imago, space acts as sort of a filter. Intertwined personal, collective and spatial identity create imago of us, which we adopt as an image of how we should be and how our space should be in relation to us. However, feedback from this imago indicates incoherency when we observe it through reality of space we inhabit. This creates a split in our identity - between internal self and our internal Otherness (Lacan's alienating identity, which is simply our awareness of not being complete in comparison to our imago). This split also others the representational - the imago from us, and indicates the presence of different imagos, that are Other to the one we are identifying with.

Process of reflection and Othering is subliminal and constant, indicating that our "chase" for becoming the imago is positioning us in the liminal state of identity between the one we used to be and the one we strive to be. This maintains the internal and external Otherness and makes identity an autopoietic system.

\section{Place Attachment as a Communicative Event}

Personal, collective and spatial identity are intertwined and perceived as relatively stable, even though they are created by ever changing socio-spatial categories. This subtle, yet, through temporal progression meaningful changeability, implicates (spatial) identity as a perpetually liminal process. 
Victor Turner (1969) recognizes three phases of process of liminality preliminal (separation), liminal (transition) and postliminal phase (incorporation). Separation includes the symbolic designation of separation from the previously established state. During the phase of transition, the features of the subject are ambiguous, with little or no attributes of a past or future state. In the state of incorporation, the act of passing is consumed, and the subject is in a relatively stable state in accordance with new circumstances and structure - incorporation is the key process for overcoming the liminal (transitional) phase and creating (perceived) ordered totality; it can be mediated by rites of passage. In general, we recognize liminality within moments of change, where something needs to reinvent itself in order not to disappear. In terms of (spatial) identity, once it reinvents itself, new process of reflection triggers new changes and new reinventions. The magnitude of reinvention depends on environmental triggers.

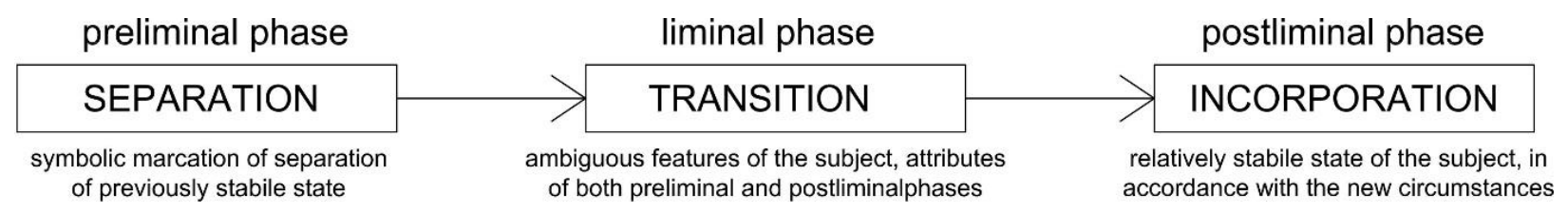

Figure 4. Turner's liminality phases (illustration: Katarina Bošnjak, February 2020.)

As mentioned, process of place attachment is a bridge between personal, collective and spatial identity. Place attachment leads to transmutation of person's and collective's relation to space, via three chosen aspects - the ritual, (collective) memory, and architecture, as established information within the process of autopoiesis.

\section{* The Ritual}

Founding new cities is a rarity today, so to analyze liminality of gaining physicality and permanence of a city, we need to go back to the past. First cities were founded as an act of imitation of universe, through elaborate ceremonial rituals, commemorated through recurring festivals, "enshrined in monuments whose physical presence anchored the ritual to the soil" (Rykwert, 1988). Within the concept of liminality - in preliminal phase, city is a mental concept without the 
attachment to place. Liminal phase is the transition from the mental concept imago mundi, to the actual place through ritual. Once the space for the new city was chosen, the land was divinized through sacrifice ${ }^{4}$, and the borders of the city were marked. Postliminal phase is achieved through laying out the city structure and its' incorporation into daily interactions of its' inhabitants. This, eventually, is how the spatial identity is achieved - through becoming the canvas for social organizations and interactions.

The ritual of founding the city is, in a way, always an "anamnesis - a reminder of the divine 'introduction' of the center of the world. Therefore, builders cannot arbitrarily choose a place to build a city, but must "discover" it through divine interaction" (Rykwert, 1988:89). This divine interaction is discovered in preliminal phase of city founding ritual, however, its echoes are maintained in the postliminal phase, through belief in apotropaic presence of deities in city and home. It is important to note that this ritual behavior is not limited to city founding, but organization of some of its spaces as well. For example, the boundaries of the templum were conceived in the same way - although they possessed visible, physical boundaries, their concept was based on ritual words, which established a magical network around the space of the temple. Words established boundaries into space, but the walls became their materialized expression. Nowadays, there are celebratory openings of new buildings and public spaces, as an act of their incorporation into everyday use, which can be perceived as a ritual and a rite of passage.

Ritual is a sequence of activities that help us overcome the liminal phase and ambiguity of something that we perceive as unfinished or undefined. In terms of autopoietic process, it is an information. This information carries the intention of anchoring the mental concept of a space to definitive point in space. It is uttered through the nature of these rituals and their intended meanings (by the subject who performs them). The understanding of this information is determined by its future users' perception, meaning it is changeable through time, based on the future circumstances. Finally, acceptance or rejection of intent and meaning of information is planted into place attachment, which materializes (future) spatial identity. As the understanding of the information is constantly retroactively reviewed since the environment is perpetually changing, this leaves the process of place attachment in constant state of liminality, triggering the process of autopoiesis and new reinvention of the (identity) system.

${ }^{4}$ Geomancy, feng-shui, dowsing are also forms of divination. 


\section{* Memory}

Once the physical structure of the city is established, it becomes receptive to the historical layering that comes with time. Urban trauma and changes in political and ideological organization, physical, cultural, demographic, economic, even ecological changes, leave marks and transform the cities' structure - at least the representation of its spaces and its' representational spaces ${ }^{5}$. This produces physical and social manifestations of memory and mnemonic residues, which become a part of cultural memory and partake in creation of identities and imaginative geographies. We should perceive memory as a motoric force - even though it is rooted in the conceptualization and representation of past, it is a driving force for our projection of the future; it comes from the imaginarium, to sustain and create the imaginarium, thus it is liminal.

To transgress the collective (and spatial) memory to the concept of autopoiesis, we need to be aware that memory (the information within autopoietic process) is a fluid matter - it exists at the intersection of lived and representational. We maintain it through symbols, text, discourse and rituals (festival, memorials, holidays...) - these represent the utterance of information, but we often maintain subjectivity towards it, which makes us prone to manipulation and/or dogmatic relationship with our past, present and future (which represents the understanding). Assman (2005:89-90) observes memory through mythical and historical time, opposing myth (fiction) to reality (history), and value expediency of myth to pointless objectivity (history). However, driving force behind our evolution is the process of internalization of our historical existence (which includes fiction and reality), and externalization of it through place attachment and spatialization of (collective) memory. This existence at the intersection of past and present, fiction and reality, lived and representational is what makes memory liminal, and spatialization of it is the act of incorporation (liminal phase) of spatial identity that "attaches" to that place of memory. This means that memory is also under constant retroactive revision, and its spatialization and meaning it gains through place attachment is continuously reinvented, based on new circumstances and interactions, which makes memory an incentive for autopoietic processes within the system of identity.

\section{* Architecture}

The most corporeal medium of this spatialization is architecture. Cedric Price said architecture is "a slow medium" (2003:57), describing temporal progression of it

${ }^{5}$ For further reading see (Lefebvre, 1974, 1984). 
gaining various meanings. Same as the city, architecture (the information) is, at first, a mental concept aspiring to personify imaginarium, displaying features of certain historical era, style, type, architect's preferences, relationship with context. To paraphrase Henri Lefebvre (1974, 1984:220) - architecture offers members of society an image of that membership (the utterance), offering them a "recognition effect" (the understanding), which is achieved through interaction with architecture and decoding of its messages. In short, when a building "receives" its physical components, it is subjected to interactions with its physical and social milieu, through which it becomes a constitutive part of spatial identity.

In context of liminality, preliminal phase of creation of architecture (or urban artefacts) is the mental concept ${ }^{6}$, which is a result of various physical, cultural and personal circumstances, followed by liminal phase - incorporation through ubication of this mental concept, and by postliminal phase, which is the start of daily use of building/space. In terms of long term, continuous transformation of architecture, we can say that, since architecture is always on the threshold between past and future, it is always at the liminal phase, always echoing with voices of past, while simultaneously embodying projections of future it represents.

As said, architecture is the third scenario of place attachment process within identity system, however, it is important to note that architecture is the medium for both previous scenarios - architecture as ritual intermediary, and architecture as a vessel for memory. In ritual, architecture becomes an anchor for magical and cosmic forces that drive our world. This ritual intent is an important memory layer, especially if it exists within the sacral dimension of architecture and religious collective identity. Historical changes and events that (abruptly or slowly) affect the way people interact with architecture also become memory layers ${ }^{7}$ (often externalized on buildings), through which buildings/public spaces can transform their status and position in collective and spatial identity. In certain occasions, this leads to functional transformation of building that does not correspond to the image of that building and the function it should contain, which creates a liminal ambiguity of spatial identity ${ }^{8}$, or esthetic transformation through overemphasizing

\footnotetext{
6 This mental concept is not necessarily the architects', it is a mental concept of society seeking to personify it's ideals through architectural medium.

7 Not all buildings „react“ to changes in the same way - architecture that contains language of ideological power can be shuned after a regime change, but residential buildings from the same era remain mostly inert, because their language is the one of function.

8 This is recognizable in inapropriate building conversions that had strong identity in their previous state into new state with function that can be considered incompatible - conversion of churches and temples into hotels is often regarded as such. However, resistance to this conversion depends on the embededdness of the previous state in the collective identity.
} 
past identity narratives ${ }^{9}$. This ambiguity actually stems from contradiction between expectation we create through architectural representation and truth - the reality of its daily use. These are, also, all environmental triggers for the process of autopoiesis within the system of identity - perpetual liminality of architecture opens up the possibilities for new decisions within these communicative events that resonate within (spatial) identity.

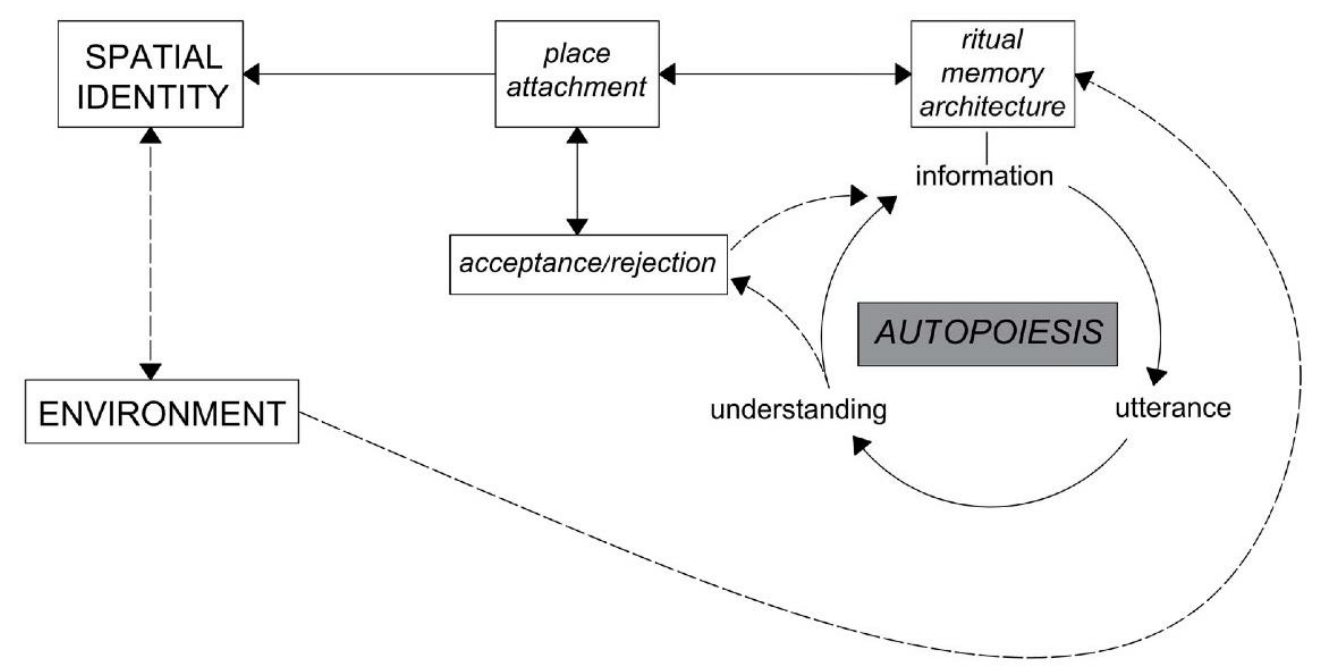

Figure 5. Connection of place attachment to autopoietic process and spatial identity system overview (illustration: Katarina Bošnjak, March 2021.)

\section{Conclusion}

Our environment is complex, it is an "amalgamation of buildings and people, inhabited settings from which daily rituals - the mundane and the extraordinary, the random and the staged - derive their validity" (Kostof, 1991:11). It "encapsulates an extraphysical reality" (ibid:25), it memorializes "human struggle and glories" (ibid:16) and sets "past and pride on display" (ibid), and through absorption and transformation of existing socio-spatial components, it derives factors of (spatial) identity. Our environment plays a key role in the discovery of our private identity, as well as creation of our collective identity. Through the inhabitation and participation in space, we create identitarian bonds with our environment, which, through the process of place attachment via rituals, memory

9 This scenario is characteristic of political and/or ideological shift, that tries to communicate this shift and the projection of new identity through revival of past and nostalgic identity. 
and architecture incorporate spatial, collective and personal identity into a complex system.

The main premise of this article was that (spatial) identity is an autopoietic system, and it was contemplated through transgression of the concept of liminality within (spatial) identity and the factors that lie beneath its transformation, whilst regarding these factor as autopoietic communication "events" that maintain its autopoiesis. Even though changes of (spatial) identity are mostly slow and almost unnoticeable in the present moment, they are constant. Identity exists on a threshold between our internal self and internal Otherness, as well as our past and projections of our future, maintained by the interaction of the elements of its' system. This means that the identity (system) is in the state of permanent liminality, which is an operative process reacting to the interactions of elements of the identity (system), as well as a product and the initiator of autopoietic processes within the identity.

To analyze identity as an autopoietic system, we applied Luhmann's transgression of the concept of autopoiesis of living systems to social (and psychic) systems. He suggested that communications are a mode of autopoietic reproduction, composed of three components: information, utterance and understanding. Thus we regarded (spatial) identity as a communication system, and the components of the process of place attachment (ritual, memory and architecture) as the information within that system. Their utterance depends on their representation(s), which stems from the intentions of the information, which depends on the structure of the system. Understanding of information is based on the perception of the intended meaning. The acceptance or rejection of the understood information defines the features of the process of place attachment. The positional relativity of subjects included in this complex process ensures the production of new elements and new meanings that seek place within the structure of the system, which makes the system of identity in constant state of change, thus perpetually liminal. This changeability and liminality maintains the autopoietic process of system elements' (re)production.

To conclude, it is important to understand the autopoiesis od (spatial) identity since it reveals its' complexity and stratification of its' processes. The interaction of elements of the system of (spatial) identity are directing consciousness and cognition (as a great part of identitarian construct), which, in turn, directs future interactions of elements within the system. This means that, in time, active, conscious perception of the environment becomes a passive, subconscious one. Finally, this transformation of modus of perception emphasizes that the system is 
susceptible to change, which produces new elements that lead to future transformations.

\section{References}

Anderson, B. (1983, 2006). Imagined Communities: Reflections on the Origin and Spread of Nationalism. London, New York: Verso.

Aquile, I., Lekovic, M., \& Sanchez, J. R. (2014). "Urban Trauma and Self-

Organization of the City. Autopoiesis in the Battle of Mogadishu and the Siege of Sarajevo ", Urban, 63-76.

Assman, J. (2005). Kulturno pamćenje: Pismo, sjećanje i politički identitet u ranim visokim kulturama. Zenica: Biblioteka Tekst.

Kostof, S. (1991). The City Shaped: Urban Patterns and Meanings Through History. London: Thames.

Lacan, J. (2006). Écrits: The First Complete Edition in English. New York, London: W. W. Northon\&Company.

Lefebvre, H. (1974, 1984). Production of Space. Oxford, Cambridge: Blackwell.

Price, C. (2003). Re: CP. (H.-U. Obrist, Ed.) Basel: Birkhäuser.

Rykwert, J. (1988). The Idea of a Town: The Anthropology of Urban Form in Rome, Italy and the Ancient World. London: The MIT Press.

Said, E. W. (1978, 1995, 2003). Orientalism. London: Penguin Books.

Seidl, D. (2004). "Luhmann's theory of autopoietic social systems", Munich Business Research, 1-28.

Turner, V. (1969). The Ritual Process: Structure and Anti-Structure. Chicago: Aldline Publishing.

Turner, V. (1974). "Liminal to liminoid in play, flow and ritual: An essay in comparative symbology", Rice University Studies, str. 53-92.

Varela, F., Maturana, H. R., \& Uribe, R. (1981). "Autopoiesis: The Organization of Living Systems, Its Characterization and a Model", Cybernetics Forum, 7-14. 